\section{UM OUTRO HORIZONTE EM BUSCA DA HUMANIZAÇÃO DA GEOGRAFIA}

Márcio Luis Fernandes'

\section{Primeiras paLAVRAS}

Na concepção de Lowenthal (1982, p. 137), uma geografia memorável não estaria atrelada a meros textos de compêndios - muito menos a perspectivas generalizantes que ignoram as particularidades, as individualidades e as singularidades - "[...] mas estudos interpretativos incorporando um acentuado ponto de vista pessoal". Seguindo tal premissa, entendemosque uma geografia comprometida comaspectos universalizantes que abarcam a sociedade como um todo, eximindo os universos particulares dos indivíduos e grupos sociais, não pode dar conta de uma geografia genuinamente humana e pessoal, forjada por cada geógrafo informal em seu mundo vivido (LOWENTHAL, 1982; COSGROVE, 2004).

Por menosprezar o rico material representado pelas experiências do mundo vivido, bem como as concepções que derivam dessas vivências, "a geografia trilhou um longo caminho até introduzir o homem como ser pensante em suas pesquisas" (MELLO, 1991, p. 1). No início dos anos 1970, no entanto, alguns geógrafos frustrados com uma geografia onde o ser humano representava apenas mais um elemento da paisagem estudada (MORAES, 2007), "começaram a buscar nas filosofias do significado respostas para suas angústias" e caminhos para o rompimento com os pressupostos positivistas e

1 Professor com especialização em Políticas Territoriais no Estado do Rio de Janeiro (UERJ - 2006); mestrado em geografia (UERJ - 2010) e doutorando em geografia (UERJ -2012).marcio_fernandes@oi.com.br.

$\triangle$ Rua Professor Castro Rebelo, 245, (llha de) Guaratiba, Rio de Janeiro, RJ. 23020090 .

Geograficidade | v.4, n.1, Verão 2014

ISSN 2238-0205 neopositivistas que predominavam na ciência geográfica (MELLO, 1990, p. 22). Surgia a geografia humanista, uma perspectiva que focaliza o homem no centro de todas as coisas, uma vez que todo ser humano pensa e filosofa, sendo portanto capaz de refletir sobre os fenômenos do(s) mundo(s) vivido(s) (RELPH, 1976; BUTTIMER, 1982; TUAN, 1982; MELLO, 2000).

\section{UM OUTRO HORIZONTE EM BUSCA DA HUMANIZAÇÃO DA GEOGRAFIA}

O movimento humanista destaca o homem e o trata com seus significados, valores, objetivos, dilemas e ações em oposição ao enfoque abstrato, mecanicista e determinista dos paradigmas anteriores. A crítica à visão reducionista do homem, principalmente após 1970, favoreceu aos geógrafos humanísticos a interpretação do sentimento e a compreensão das relações entre os homens e seu mundo vivido. Essa perspectiva, ao defender a dimensão subjetiva e a experiência vivida pelos indivíduos e grupos sociais, propõe uma compreensão do mundo humano através do estudo das relações das pessoas com a natureza, do seu comportamento geográfico, bem como dos seus sentimentos e ideias a respeito do espaço e do lugar (TUAN, 1982; 1983).

As ideias acima citadas surgem como relevantes para esta tendência geográfica. No lugar o indivíduo se encontra ambientado e mesmo integrado. Tal expressão conceitual compõe este mundo pleno de sentimentos e afeições, um centro de significância ou um foco de ação emocional do homem. O lugar não é toda e qualquer localidade, mas aquela que exprime afetividade e valores para o indivíduo ou a sua coletividade (CHRISTOFOLETTI, 1982). Em contraponto, o espaço é representado por qualquer porção da superfície terrestre, sendo amplo, desconhecido, indiferenciado, rejeitado ou mesmo odiado 
(TUAN, 1982; 1983; 1998; MELLO, 1990; 1991; 2001), possivelmente a ser capturado ou conquistado.

Apesar da distinção entre esses conceitos-chave da geografia em geral (CORRÊA, 2002) e da ramificação humanista em particular (HOLZER, 2001; 2008), na experiência, o significado de espaço pode se fundir e/ou confundir com o de lugar. $\mathrm{O}$ que começa como espaço indiferenciado transforma-se em lugar à medida que o conhecemos melhor e o dotamos de valor (TUAN, 1983). Segundo Mello:

Certos espaços só se tornam lugares após uma demorada experiência. $\mathrm{O}$ que inicialmente é feio ou até mesmo odiado, com o tempo ganha foros de lugar. Espaços se tornam lugares em razão do contato com outras pessoas e em trocas afetivas, econômicas etc. (MELLO, 1990, p. 105)

A geografia humanista está preocupada com a dimensão afetiva em meio ao vivido/existencial. Assim sendo, é fundamental para os geógrafos de inspiração humanista, não a "distribuição espacial dos fatos sociais, mas a maneira como as pessoas vivem nos lugares onde residem ou os que visitam, deles extraindo uma experiência" (CLAVAL, 2001, p. 46). Nessa trilha, estar junto, estar próximo, não significa a proximidade física, mas o relacionamento afetivo com outra pessoa ou com outro lugar (CHRISTOFOLETTI, 1982). Lugares e pessoas fisicamente distantes podem estar afetivamente muito próximos. Portanto, o estudo do espaço remonta à análise dos sentimentos e ideias espaciais das pessoas e grupos de pessoas (TUAN, 1982). Sob a perspectiva positivista, a geografia diz respeito à análise da organização espacial. Sob o horizonte humanista, espaço e lugar assumem características muito diferentes (CHRISTOFOLETTI, 1982), cabendo ao geógrafo da ala humanista traduzir o que representam por meio de uma estrutura coerente (CHRISTOFOLETTI, 1982; TUAN, 1982).

Geograficidade | v.4, n.1, verão 2014 ISSN 2238-0205
Da valoração das atitudes decorre a preocupação com gostos, preferências, características e particularidades dos lugares. Valorase também "o contexto ambiental e os aspectos que redundam no encanto e na magia dos universos vividos, na sua personalidade e distinção" (CHRISTOFOLETTI, 1982, p. 23). Há então o entrelaçamento entre a pessoa ou grupo social e o lugar, uma vez que o indivíduo não é distinto de seu mundo vivido (RELPH, 1976).

Tuan (1982, p. 159), por seu turno, relata que "a contribuição da geografia humanística para a ciência está na revelação de materiais dos quais o cientista, confinado em sua própria estrutura conceitual, pode não estar consciente". Para o pesquisador:

Esse material inclui a natureza e a gama de experiências e pensamentos humanos, a qualidade e a intensidade de uma emoção, a ambivalência e a ambiguidade dos valores e atitudes, a natureza e o poder do símbolo e as características dos eventos, das intenções e das aspirações humanas (TUAN, 1982, p. 159160).

Para elucidar esse mosaico de objetos materiais e imateriais em meio à indivisibilidade sujeito/objeto, o geógrafo humanístico:

[...] deve ter um interesse penetrante pela filosofia, pois esta levanta questões fundamentais de epistemologia para as quais podemos buscar explicações no mundo real. A filosofia proporciona também um ponto de vista unificado a partir do qual toda uma série de fenômenos humanos pode ser sistematicamente avaliada (TUAN, 1982, p. 161).

Nestes termos, estamos falando da hermenêutica, que segundo Eliade (1971), é o único método eficaz de interpretação do qual o humanismo não pode se privar, e da fenomenologia, na qual a geografia humanista busca elementos para pautar suas pesquisas (GOMES, 2007). 


\section{AS FILOSOFIAS DO SIGNIFICADO: FUNDAMENTOS METODOLÓGICOS DA GEOGRAFIA HUMANISTA}

Apoiada nos princípios da fenomenologia e da hermenêutica, a geografia humanista tem interesse em entender a alma dos lugares a partir das experiências vividas pelos indivíduos e grupos sociais. Esta perspectiva entende ser o lugar parte integrante do ser, sendo cada indivíduo um geógrafo informal capacitado para discorrer sobre a alma dos lugares, por ser o homem quem produz, aprende, vive e transmite geografia (SCHUTZ, 1979; BUTTIMER, 1982; LOWENTHAL, 1982; COSGROVE, 2004; MELLO, 2004; 2005; 2007).

"A fenomenologia é a filosofia presente em um número maior de estudos humanísticos em geografia" (MELLO, 1991, p. 36), sendo também considerada um método de investigação (ARANHA, 1996; GOMES, 2007). "Seu criador, o filósofo alemão Edmund Husserl (1859 -1938) critica as teorias científicas, particularmente as de inspiração positivista, excessivamente apegadas à objetividade e à crença de que a realidade se reduz àquilo que se percebe pelos sentidos" (MELLO, 1991, p. 36).

Etimologicamente, fenomenologia é o estudo do fenômeno, sendo seu papel analisar a dinâmica que fornece sentido e significado aos objetos, tratando o mundo e os seres humanos de uma maneira indissociável (SCHUTZ, 1979). Examinando o conceito de fenômeno, que em grego significa o que aparece (ARANHA, 1996), compreendemos melhor que a fenomenologia trata do conhecimento como ele surge, isto é, como se apresenta à consciência. Como fonte de significado para o mundo, a consciência não se restringe ao mero conhecimento intelectual, mas é geradora de intencionalidades não só cognitivas como afetivas e práticas. O olhar sobre o mundo é o ato pelo qual o homem o experiencia, imaginando, julgando, amando, temendo (SCHUTZ, 1979; ARANHA, 1996).

Geograficidade | v.4, n.1, Verão 2014

ISSN 2238-0205
A fenomenologia critica a tendência naturalista que orienta o método das ciências humanas. Para esta filosofia, não há fatos com a objetividade pretendida pelo positivismo, já que não entendemos o mundo como um dado bruto, desprovido de significados. O mundo que decodifico é um universo para mim, daí a importância do sentimento, do entendimento e da rede de significações que envolvem os nossos universos vividos (ARANHA, 1996). Para Schutz (1979), o ponto de partida irredutível para as bases fenomenológicas diz respeito às experiências do ser humano consciente, que vive e age em um mundo que ele capta, interage e interpreta - assumindo significados múltiplos.

Como experiência é sempre vivência de alguma coisa, todas as experiências diretas de seres humanos são experiências em e de seu mundo vivido, elas o constituem, são dirigidas a ele, são nele testadas e vivenciadas. O universo vivido é simplesmente toda a esfera das experiências cotidianas, direções e ações através das quais os indivíduos lidam com seus interesses. De acordo com a filosofia fenomenológica, cada indivíduo constrói o seu próprio mundo. Assim, subjetivamente, duas pessoas jamais poderiam vivenciar a mesma situação da mesma forma (SCHUTZ, 1979). Neste particular, Buttimer (1982, p. 167), assinala que:

os fenomenologistas têm sido os porta-vozes mais sistemáticos deste esforço. Desafiando muitas das premissas e dos procedimentos da ciência positiva, expuseram uma crítica radical do reducionismo, da racionalidade e da separação de "sujeitos" e "objetos" na pesquisa empírica. Com os existencialistas, apregoam o argumento da libertação da experiência vivida, apelando por descrições mais concretas do espaço e do tempo, e de seus significados na vida humana diária (SCHUTZ, 1979, p, 167).

Por contemplar como traço comum a inseparabilidade sujeitoobjeto, a fenomenologia examina de maneira radical os fenômenos 
da consciência ou da experiência vivida, busca os fatos como são produzidos, interpretando a apreensão da essência e desta maneira investiga os atos e o entendimento sobre o mundo vivido. Neste contexto:

O lugar surge como conceito-chave na geografia humanística advindo da noção fenomenológica de mundo vivido emocionalmente, modelado, introjetado e revestido de eventos, pessoas, itinerários, lutas, ambiguidades, envolvimentos, sonhos, desatinos, "canções que minha mãe me ensinou", base territorial e toda sorte de elementos que permite à pessoa se sentir em casa ou, por outro lado, distanciada em meio a um estranhamento topofóbico (MELLO, 2005, p. 34).

Por muito tempo os geógrafos excluíram de suas abordagens os laços de vizinhança, o estoque de conhecimento, a agradabilidade, a topofobia, a fixação aos espaços e lugares, as experiências cotidianas e os elos que unem as pessoas ao meio ambiente. A fenomenologia, considerando esses atributos, serve de ponte a esses especialistas, com vistas ao entendimento do mundo vivido, pois - diferentemente da ciência que omite as questões da vida - não trata o mundo independente dos seres humanos (MELLO, 1991).

Com respaldo no mundo vivido, o geógrafo pode entender como nasce a magia dos lugares, as particularidades intrínsecas de cada porção territorial, a distinção de diferentes pontos da cidade, o encantamento, o desprezo, a atração e o que é típico dos lugares (MELLO, 1991).

O mundo vivido é a consciência e o ambiente íntimo de cada um, emocionalmente modelado e revestido de eventos, relações, ambiguidades, envolvimentos, valores e significados, o que compreende os seres humanos com toda ação e interesses humanos, trabalhos e sofrimentos (MELLO, 1991).

Geograficidade | v.4, n.1, Verão 2014

ISSN 2238-0205
O mundo vivido de cada um já existia antes do nascimento da pessoa, que vivencia e interpreta seu mundo a partir de valores e estoques de experiências pessoais, e também por meio de outros indivíduos que Ihe transmitem conhecimentos pretéritos e hodiernos (MELLO, 2000).

A intersubjetividade, ou intermundo, é o mundo comum a diferentes pessoas, cenário e objeto das ações e das interações dos seres humanos. O mundo vivido, continuamente experienciado, é modificado pelas ações humanas, que também modifica as suas ações (MELLO, 1991). "Já o estoque de experiências é um enriquecimento cotidiano, prático e teórico, que fornece ao homem elementos para agir e pensar" (MELLO, 1991, p. 38). "No entanto, este conhecimento não é homogêneo e sim incoerente, parcial, contraditório e ambíguo" (MELLO, 2000, p. 58). "O conhecimento do mundo, recebido pela cultura formal e informal, e completado pela experiência pessoal, gera intimidade e afetividade pelo lugar vivido" (MELLO, 2000, p. 58). Este mundo que, para a fenomenologia é o contexto dentro do qual a consciência é revelada, ocorre à nossa experiência e interpretação (ELIADE, 1971; BUTTIMER, 1982; MELLO, 2005; GOMES, 2007).

A hermenêutica é outra filosofia do significado utilizada pelos geógrafos humanistas, tendo como precursor o alemãoWilhem Dilthey (1833-1911) que adicionou a este movimento filosófico - próximo da fenomenologia de Schutz - elementos da importância interpretativa (MELLO, 1991). A origem do termo se situa na antiguidade, inspirada na mitologia grega de Hermes, deus da comunicação, encarregado de trazer as mensagens do Olimpo (GOMES, 2007). Utilizada originalmente pelos antigos teólogos como metodologia própria à interpretação da Bíblia, o termo passou posteriormente a designar todo esforço de interpretação científica de um texto difícil que exige uma explicação. Contemporaneamente, a hermenêutica constitui uma reflexão filosófica interpretativa ou compreensiva sobre os símbolos, 
sendo fundamental em todas as humanidades e em todas as disciplinas que se ocupam com a interpretação das obras dos homens (PALMER, 1970; JAPIASSÚ; MARCONDES, 2006; ABBAGNANO, 2007).

"Na hermenêutica", como na fenomenologia, "não há separação entre sujeito e objeto". Assim sendo, esta "filosofia interpretativa tenta explicar os conteúdos da mente e outros aspectos da experiência vivida" em meio à introjeções, onde os indivíduos e grupos sociais não são dissociados de sua base territorial experienciada. Cabe ao geógrafo esclarecer o significado dos conceitos, símbolos e aspirações, à medida que tudo isso está atrelado ao espaço e ao lugar. Ou seja, "o geógrafo humanístico tem como tarefa interpretar a ambivalência, ambiguidade e complexidade da consciência dos indivíduos e/ou grupos sociais a respeito do meio ambiente" (MELLO, 1991, p. 42).

Vale ressaltarque "asfronteirasentrefenomenologiaehermenêutica não são muito rígidas". Assim sendo, "vários geógrafos humanísticos entre eles Tuan, Buttimer, Lowenthal e Relph-embora se classifiquem como fenomenologistas, exibem o movimento hermenêutico de forma inconfundível" (MELLO, 1991, p. 42).

Na vertente humanista, vale repetir, a distribuição espacial dos eventos e fatos sociais não representa o elemento determinante da pesquisa. O fundamental para os geógrafos deste horizonte é a maneira existencial de viver das pessoas nos lugares onde residem ou os que visitam, deles extraindo experiências (CLAVAL, 2001).

\section{DECODIFICANDO CONCEITOS E TEMAS HUMANÍSTICOS}

Comumente, os conceitos de espaço e lugar expressam - metafórica e respectivamente - as noções de escuridão e luminosidade (MELLO, 2000). No entanto, longe dos ditames positivistas e neopositivistas, não há uma regra preestabelecida para que espaços opacos, imersos por penumbra, alcem, através de sua iluminação ou claridade, ao patamar de lugar. Parafraseando Mello (2003), podemos apontar que o lugar pode perder ou receber tal condição dependendo das trevas ou do brilho com que o mesmo é embotado ou iluminado no transcurso do tempo. Em Tuan (1983, p.179) o "lugar é qualquer objeto estável que capta nossa atenção". Sendo assim, "muitos lugares, altamente significantes para certos indivíduos e grupos, têm pouca notoriedade visual" (TUAN, 1983, p. 180). Por maior que seja sua opacidade ou visibilidade, certos objetos ou lugares que são admirados por uma pessoa, podem não ser notados por outra (TUAN, 1983).

Para Tuan (1983, p. 184), o lugar é também "um reservatório de lembranças e sonhos". Nesse ínterim, a notoriedade visual apenas, não se configura como uma garantia de que certos espaços tornemse lugares. O profundo sentido de lugar resulta de uma combinação de fatores e valores históricos, culturais, econômicos, locacionais, existenciais, subjetivos, intersubjetivos, invisíveis e visuais (YÁZIGI, 2003). No tocante à linha de pensamento aqui empreendida, a visibilidade não estaria atrelada apenas às construções humanas e aos elementos da natureza que conferem valores visuais a determinados fixos. No entanto, não há como negar que esses atributos culturais e naturais, em muitos casos, representam fatores de transformação de determinadas localidades que, com isso, podem sofrer mudanças qualitativas ou não-qualitativas, dependendo das diferentes perspectivas de seus vivenciadores. Em relação ao ponto-de-vista diferenciado dos indivíduos com relação à visibilidade, Tuan (1983, p. 184) sublinha que "[...] a maioria dos lugares não são criações deliberadas, poissãoconstruídos para satisfazernecessidades práticas". Nesse contexto, os mesmos adquirem visibilidade e significado tanto para os habitantes locais como para os de fora (TUAN, 1983). 
NaconcepçãodeGomes (2007), a primeiracaracterísticafundamental do humanismo retomada pela geografia concerne na incontornável visão antropocêntrica, segundo a qual o homem é a medida de todas as coisas. Ademais, os seres humanos, individualmente ou em grupos, tendem a situar o seu lugar vivido como o centro do mundo. Neste contexto, o egocentrismo e o etnocentrismo tornam-se traços humanos universais (TUAN, 1980). Com base em Tuan (1980), Mello descreve o etnocentrismo como:

Um fenômeno universal de supervalorização do "centro", "umbigo", "mais saudável" ou "melhor lugar do mundo" e pode também ser compreendido como egocentrismo coletivo. As pessoas do "centro" estabelecem discriminação entre "nós" ("superiores") e "eles" ("de menor valor", "de cultura inferior") olhando para estes de forma "blasé" e, por vezes, com apatia, sarcasmo ou agressividade (MELLO, 1991, p. 202).

A noção de centro é uma das mais relevantes manifestações culturais, uma vez que, comumente, as pessoas tendem a situar o lugar em que vivem como o mais importante e favorável, e como o centro do seu mundo. "Todos os povos antigos põem-se como centro das relações e organizam o que entendem por mundo nessa referência". Nesse sentido, o topo é uma noção correlata. "Todo um simbolismo religioso e cartográfico deriva dessa centralidade, organizando a concepção e a relação geográfica desses povos" (MOREIRA, 2009, p. 67). De acordo com crenças indianas, o Monte Meru estaria erguido no centro do mundo. Já uma crença iraniana afirma que a montanha sagrada de Elburs estaria situada no ponto central da Terra. O nome do Monte Tabor, na Palestina, poderia significar "umbigo". O monte Garizim, na região central da Palestina, sem dúvida alguma desfrutava do prestígio de lugar central, pois era chamado de "umbigo da Terra" (ELIADE, 2007). A Palestina, segundo antiga tradição até hoje preservada na região, na sua condição de país mais alto por estar perto do cume da montanha cósmica, não teria sido encoberta pelo dilúvio. Um texto rabínico afirma: "A terra de Israel não foi submergida pelo dilúvio". Para os cristãos,

O Gólgota estava situado no ponto central do mundo, já que era o cume da montanha cósmica e, ao mesmo tempo, o lugar onde Adão tinha sido criado e sepultado. Assim, o sangue do Salvador é derramado sobre o crânio de Adão, enterrado precisamente aos pés da Cruz, servindo para sua redenção. A crença de que o Gólgota estaria situado no centro do mundo ainda é preservada no folclore dos cristãos orientais (ELIADE, 2007, p.24).

Pormeio das crenças as quais fazemos menção podemos depreender que cada cidade oriental estava localizada no centro do mundo. Para alguns desses povos, o ponto mais alto da montanha cósmica não seria apenas o ponto mais elevado da Terra, mas também o umbigo do mundo, o ponto no qual começou a criação. Algumas tradições explicam o simbolismo do centro em termos tomados da embriologia, segundo o qual "o Ser Divino criou o mundo como um embrião. Do mesmo modo que o embrião começou a passar do umbigo em diante, Deus começou a criar o mundo do umbigo em diante, e a partir daí, ele se espalhou em diferentes direções" (ELIADE, 2007, p. 25). Nesse ínterim, o mundo teria sido criado a partir de Sião e o universo concebido a partir de um ponto central. A criação do homem também teria acontecido em um ponto central, no centro do mundo (ELIADE, 2007).

Segundo tradição mesopotâmica, o homem teria sido formado no "umbigo da Terra". Assim sendo, o Paraíso, onde Adão foi criado a partir do barro, encontra-se localizado no centro do cosmo. O Paraíso era o umbigo daTerra, e, segundo uma tradição síria, teria sido estabelecido em uma montanha mais alta do que todas as outras. Adão teria sido 
criado no centro da Terra (ELIADE, 2007). Partindo da premissa de que a criação derivou a partir de um centro, podemos presumir igualmente que qualquer lugar fundado tem sua edificação no centro do mundo dos indivíduos que o estabeleceram como lar, abrigo, refúgio e morada.

Diferentemente da teoria social crítica tradicional-na qual o conceito de lugar está vinculado à esfera local (CARLOS, 1996; SANTOS, 2002) na perspectiva humanista, tal aforismo, por não possuir escala definida, torna-se demasiadamente difuso uma vez que, tanto pode designar um assento, quanto abarcar o mundo todo (TUAN, 1983). Todavia, o mesmo Tuan que retoma a máxima que define a Geografia como "o estudo da Terra como o lar das pessoas" (TUAN, 1991, p. 89), aponta também que "[...] a topofilia soa falsa quando é manifestada por um extenso território" (TUAN, 1980, p. 116). No entanto, o amor patriótico, significativo em sua dimensão, pode contrariar suas elucubrações. Para o citado geógrafo, os sentimentos topofílicos necessitam de "[...] um tamanho compacto, reduzido às necessidades biológicas do homem e às capacidades limitadas dos sentidos" (TUAN, 1980, p. 116). Além disso, uma pessoa pode se identificar mais facilmente com uma área, se ela indica ser uma unidade natural, pequena o suficiente para ser conhecida pessoalmente (TUAN, 1980). Nesse campo, o lugar se confunde com a esfera local, sendo também o lócus do cotidiano "responsável pelas paixões humanas por meio da ação comunicativa e por diversas manifestações da espontaneidade e da criatividade" (SANTOS, 2002, p. 322).

\section{PaLAVRAS finaIs}

Vários cientistas sociais - principalmente após a década de 1970 - têm se empenhado em criticar a visão reducionista do homem, postulada pela ciência positiva, tendência que favoreceu aos geógrafos humanistas a interpretação do sentimento e a compreensão das relações entre os homens e seu mundo. A referida corrente do pensamento geográfico se opõe igualmente ao positivismo, na tentativa de superar-lhe o reducionismo. Alguns filósofos como Wilhelm Dilthey, no entanto, na passagem entre os séculos XIX e $X X$, já criticavam a tendência cientificista, naturalista e positivista que norteava as ciências humanas de então. Para o citado cientista, precursor da hermenêutica, os fatos referentes ao espírito ou à alma não se assemelham aos processos naturais, por se referirem ao mundo humano da significação e do valor. Sendo assim, o nicho de valorações e demais sentimentos provenientes da subjetividade e da intersubjetividade não deve ser retirado do contexto histórico dos indivíduos e grupos sociais, não sendo possível formular leis objetivas sobre o mesmo, mas sim buscar sua compreensão e interpretação (JAPIASSÚ, 1975; ARANHA; MARTINS, 1992; ARANHA, 1996).

Neste percurso, o positivismo seria responsável por uma fábula, uma vez que por meio desta inclinação, a ciência se torna um mito, passando a ser considerada a única forma adequada de conhecimento em detrimento de outras possíveis abordagens do real. Trata-se, portanto, de uma perspectiva deformada do saber pois, ao admitir que o conhecimento verdadeiro refere-se apenas ao que pode ser provado, experimentado e, portanto, objetivo, incorre em um reducionismo que limita as abordagens referentes ao ser humano - que por pensar, sentir, sonhar e filosofar - sugere que sua subjetividade seja foco das pesquisas científicas. Aliás, foi da pretensa objetividade apregoada pelo ideário positivista que derivou o "mito da neutralidade científica", segundo o qual as pesquisas científicas estariam à margem da influência social, cultural ou política, se ocupando o cientista da descrição dos fenômenos, sem interferir nos estudos. 
A fenomenologia, como sabemos, foi uma das primeiras filosofias a fazer oposição ao reducionismo e ao cientificismo das ciências ditas positivas. Enquanto o positivismo requer um conhecimento científico cada vez mais neutro, despojado de subjetividade e, por conseguinte, distante do homem, a fenomenologia propõe a retomada da humanização da ciência, com nova relação entre sujeitoobjeto e homem-mundo, considerados metades inseparáveis. Como doadora de sentido e fonte de significado para o mundo, a consciência não se restringe ao mero conhecimento intelectual, mas é geradora de intencionalidades não só cognitivas como afetivas e práticas. O olhar sobre o mundo é o ato pelo qual o homem experiencia seu universo vivido, imaginando, julgando, amando, temendo, sonhando. Nesse sentido, o universo que vivencio é um mundo para mim, daí a importância do sentido, da rede de significações que envolve o que é captado ou compreendido sensorial, mental ou psicologicamente (JAPIASSÚ, 1975; ARANHA; MARTINS, 1992; ARANHA, 1996).

A imagem mítica do cientista ignora que ele faz parte e depende de uma estrutura real do mundo que o cerca. Essa pretensa neutralidade ignora o poder persuasivo da experiência, como se o pesquisador pudesse ser o detentor de uma verdade una que, uma vez formulada em sua coerência, estaria isenta de questionamentos; como se ele pudesse guardar para sempre a imagem de um indivíduo imune à incoerência das paixões (JAPIASSÚ, 1975). Devido a esse arcabouço positivista que, cônscia ou inconscientemente, persiste em permear boa parte das abordagens relacionadas às humanidades, habitualmente sobrevêm ao pesquisador, preocupações metodológicas como "a utilização da mesma pessoa verbal do início ao fim do texto" e - principalmente "o necessário cuidado redobrado para não incorrer no fatídico erro da parcialidade", interferindo indevidamente na pesquisa que, apesar de ser de sua autoria, não deve manifestar seu ponto de vista particular.
A liberdade é apregoada por meio das filosofias do significado norteadoras da geografia humanista que - avessa às regras positivistas, leis, modelos, certezas, precisões - defende que 0 pesquisador, envolvido no universo vivido das pessoas, pode, tanto utilizar diferentes pessoas verbais (eu ou nós, por exemplo), quanto comprometer a pretensa imparcialidade da pesquisa, defendida pelos paradigmas positivistas e neo-positivistas.

A tão largamente difundida "neutralidade científica" tornou-se mito devido ao discernimento de que toda pesquisa científica defende um determinado ponto de vista, tanto do pesquisador, quanto do grupo que ele representa, sendo por isso tendenciosa. A filosofia desmistificou essa crença e, a partir deste precedente, o humanismo passou a apregoar a inclusão dos valores humanos atrelados à subjetividade e ao intermundo em seus estudos. Uma vez que o pesquisador também representa uma parte do universo vivido pesquisado, suas experiências vivenciais não precisam mais ser desprezadas.

Diante do exposto neste breve ensaio, vale salientar neste derradeiro parágrafo que, a abordagem elaborada a partir da visão subjetiva converge para a elucidação da intersubjetividade, que para Schutz (1979) representa um estoque de conhecimentos vivenciado e interpretado por várias pessoas que funciona como uma espécie de código de referência. Nesse sentido, vivenciar determinado lugar pressupõe viver envolvido interativamente com muitas pessoas, em complexas redes de relacionamentos que convergem para a ocorrência de experiências compartilhadas. ()

\section{REFERÊNCIAS}

ABBAGNANO, Nicola. Dicionário de Filosofia. São Paulo: Martins Fontes, 2007. 
ARANHA, Maria Lúcia de Arruda; MARTINS, Maria Helena Pires. Temas de Filosofia. São Paulo: Editora Moderna, 1992.

ARANHA, Maria Lúcia de Arruda. História da Educação. São Paulo: Moderna, 1996.

BUTTIMER, Anne. Apreendendo o Dinamismo do Mundo Vivido. In: CHRISTOFOLETTI, Antônio (Org.). Perspectivas da Geografia. São Paulo: DIFEL, 1982. p. 165-193.

CARLOS, Ana Fani Alessandri. O Lugar no/do Mundo. São Paulo: Hucitec, 1996.

CHRISTOFOLETTI, Antônio. As Perspectivas dos Estudos Geográficos. In: . (Org.). Perspectivas da Geografia. São Paulo: DIFEL, 1982. p. $11-36$.

CLAVAL, Paul. O Papel da Nova Geografia Cultural na Compreensão da Ação Humana. In: CORRÊA, Roberto Lobato; ROSENDAHL, Zeny (Org.). Matrizes da Geografia Cultural. Rio de Janeiro: EdUERJ, 2001. p. 35-86.

CORRÊA, Roberto Lobato. Espaço: Um Conceito-Chave da Geografia. In: CASTRO, Iná Elias de; GOMES, Paulo César da Costa; CORRÊA, Roberto Lobato (Org.). Geografia: conceitos e temas. 4.ed. Rio de Janeiro: Bertrand Brasil, 2002. p. 15-47.

COSGROVE, Denis. A Geografia Está em Toda Parte: Cultura e Simbolismo nas Paisagens Humanas. In: CORRÊA, Roberto Lobato; ROSENDAHL, Zeny (Org.). Paisagem, Tempo e Cultura. Rio de Janeiro: EdUERJ, 2004. p. 92-123.

ELIADE, Mircea. La Nostalgie des Origines. Paris: Folio-Essais; Galimard, 1971.

Mito do eterno retorno. São Paulo: Mercuryo, 2007.

GOMES, Paulo César da Costa. Geografia e Modernidade. Rio de Janeiro: Bertrand Brasil, 2007.
HOLZER, Werther. A Geografia Fenomenológica de Eric Dardel. In: CORRÊA, Roberto Lobato; ROSENDAHL, Zeny (Org.). Matrizes da geografia cultural. Rio de Janeiro: EdUERJ, 2001. p. 103-122.

. A Geografia Humanista: uma revisão. Espaço e cultura, Rio de Janeiro, p. 137-147, 2008. Edição comemorativa 1993-2008.

JAPIASSÚ, Hilton. O Mito da Neutralidade Científica. Rio de Janeiro: Imago Editora, 1975.

-; MARCONDES, Danilo. Dicionário básico de filosofia. Rio de Janeiro: Zahar, 2006. 309 p.

LOWENTHAL, David. Geografia, experiência e Imaginação: Em direção a uma epistemologia geográfica. In: CHRISTOFOLETTI, Antônio. Perspectivas da Geografia. São Paulo: DIFEL, 1982. p. 103-141.

MELLO, João Baptista Ferreira de. Geografia Humanística: A Perspectiva da Experiência Vivida e Uma Crítica Radical ao Positivismo. Revista Brasileira de Geografia, Rio de Janeiro, v. 52, n. 4, p. 91-115, 1990.

O Rio de Janeiro dos Compositores da Música Popular Brasileira - 1928/1991 - uma introdução à geografia humanística. 1991. 3oof. Dissertação (Mestrado em Geografia) — Universidade Federal do Rio de Janeiro, Rio de Janeiro, 1991.

Símbolos dos Lugares, dos Espaços e dos "Deslugares". Espaço e Cultura, Rio de Janeiro, p. 64-72, 2003.

Dos Espaços da Escuridão aos Lugares de Extrema Luminosidade - O Universo da Estrela Marlene como e documento para a construção de conceitos geográficos. 2000. Paginação irregular Tese (Doutorado em Geografia) - Universidade Federal do Rio de Janeiro, Rio de Janeiro, 2000.

Descortinando e (Re)pensando Categorias Espaciais com Base na Obra de Yi-Fu Tuan. In: CORRÊA, Roberto Lobato; ROSENDAHL, Zeny (Org.). Matrizes da geografia cultural. Rio de Janeiro: EdUERJ, 2001. p. 87-101. 
No Pulsar da Cidade Maravilhosa de São Sebastião do Rio de Janeiro. In: SOCIEDAD LATINOAMERICANA DE ESTUDIOS SOBRE AMERICA LATINA Y EL CARIBE - SOLAR 9. 2004, Rio de Janeiro. Anais... Rio de Janeiro, 2004.

Valores em Geografia e o Dinamismo do Mundo Vivido na Obra de Anne Buttimer. Espaço e Cultura, Rio de Janeiro, v. 19-20, p. 33-40, 2005.

Os Tambores e as Flechas de São Sebastião do Rio de Janeiro. Revista Imaginário e Arte, São Paulo, n. 15, p. 37-67, 2007.

MORAES, Antônio Carlos Robert de. Geografia: pequena história crítica. São Paulo: Annablume, 2007.

MOREIRA, Ruy. O pensamento geográfico brasileiro: as matrizes da renovação. São Paulo: Contexto, 2009.

PALMER, Richard E. Hermenêutica. Edições 70. São Paulo: Martins Fontes, 1970.

RELPH, Edward. Place and Placelessness. London: Pion, 1976.

SANTOS, Milton. A Natureza do Espaço: Técnica e Tempo, Razão e Emoção. São Paulo: EDUSP, 2002.
SCHUTZ, Alfred. Fenomenologia e relações sociais. Rio de Janeiro: Zahar, 1979.

TUAN, Yu Fu. Topofilia: Um Estudo da Percepção, Atitudes e Valores do Meio Ambiente. (Trad. Lívia de Oliveira) São Paulo/Rio de Janeiro: DIFEL, 1980.

Geografia Humanística. In: CHRISTOFOLETTI, Antônio. Perspectivas da Geografia. São Paulo: DIFEL, 1982. p. 143-164.

Espaço e Lugar: A Perspectiva da Experiência. (Trad. Lívia de Oliveira) São Paulo: DIFEL, 1983.

The good life. Madison: The University of Wisconsin Press, 1986.

Escapism. Baltimore: The Johns Hopkins University Press, 1998.

YÁZIGI, Eduardo. Patrimônio Ambiental Urbano: refazendo um conceito para o planejamento urbano. In: CARLOS, Ana Fani Alessandri; LEMOS, Amália Inês Geraiges (orgs). Dilemas Urbanos: Novas Abordagens sobre a Cidade. São Paulo: Contexto, 2003. p. 253265 . 